\title{
Fagos de bactérias redutoras de sulfato em água de produção de um reservatório de petróleo offshore: método tentativo de concentração e purificação
}

\author{
Phages of Sulphate Reducing Bacteria in reactor water from \\ offshore oil wells: tentative method for concentration and purification
}
Mayara Kretzer Kremer" ${ }^{1 *} \oplus$, Dolores Ursula Mehnert ${ }^{\circledR} \oplus$, Telma Alves Monezi ${ }^{2} \oplus$,

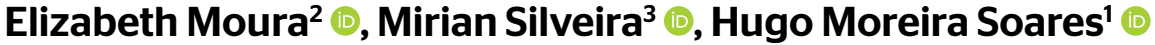

$\square$

\section{RESUMO}

O controle do crescimento microbiano é um desafio crescente na produção de petróleo e gás, uma vez que a presença de determinadas bactérias traz impactos econômica e ambientalmente negativos. As bactérias redutoras de sulfato (BRS) são particularmente problemáticas, uma vez que são responsáveis pela corrosão biológica ligada à produção de sulfeto de hidrogênio, efeito conhecido como souring. A principal forma de controle das BRS atualmente é a injeção de biocidas, no entanto essa estratégia, além de requerer aplicação contínua, tem se revelado pouco efetiva na eliminação de biofilmes e é associada a um alto risco de contaminação das águas. Portanto, é necessário que se busquem abordagens mais eficientes e específicas em relação ao controle microbiológico. O uso de vírus bacteriófagos vem ao encontro dessas necessidades, pois eles, após se multiplicarem, geralmente provocam a lise celular, liberando novas partículas virais e evitando que a bactéria se prolifere. Diante disso, este estudo propõe estabelecer um método para a concentração e a determinação da eficiência de recuperação de bacteriófagos de BRS presentes em água de reator oriunda de poços de petróleo. As amostras foram coletadas de dois reatores operados em batelada alimentada e que simulam um poço de petróleo. As amostras de água de reator foram primeiramente clarificadas, os vírus eluídos desse sedimento e, em seguida, concentrados por ultracentrifugação. O concentrado viral foi então purificado com Vertrel XF. Ensaios de semeadura experimental de miofago P1 nas amostras de água do reator revelaram taxa de recuperação viral de $27,7 \%$, contra ao $16 \%$ obtidos com outros protocolos.

Palavras-chave: bactérias redutoras de sulfato; souring; controle microbiano; bacteriófagos

\section{ABSTRACT}

The control of microbial growth is an increasing challenge in the production of oil and gas, since the presence of certain bacteria has economic and environmental negative impacts. Sulphate reducing bacteria are particularly problematic, since they are responsible for the biological corrosion associated with the production of hydrogen sulfide, an effect known as souring. The main form of control is the use of biocides; however, this strategy, in addition to requiring continuous application, has proven to be ineffective in the elimination of biofilms and is associated with a high risk of water contamination. Therefore, it is necessary to seek more efficient and specific approaches to microbiological control. The use of bacteriophage viruses meets these needs, because after they multiply, they usually cause cell lysis, releasing new viral particles and preventing the bacteria from proliferating. In view of this, this study proposes to establish a method for the concentration and detection of bacteriophages of Sulphate Reducing Bacteria present in reactor water from oil wells. The samples were collected from two reactors, operated in a batch fed to simulate an oil well. The reactor water samples were first clarified, viruses adsorbed to sediment were eluted and then concentrated by ultracentrifugation. The viral concentrate was then purified with Vertrel-XF Experimental seeding of P1 myophage in water samples from the reactor revealed a viral recovery rate of $27.7 \%$, compared to the $16 \%$ obtained by use of other protocols.

Keywords: sulphate reducing bacteria; souring; microbial control bacteriophage. 


\section{INTRODUÇÃO}

Desde o início da produção comercial de petróleo, há aproximadamente 140 anos, microrganismos vêm causando problemas, como a acidificação dos poços de petróleo. Embora os avanços recentes tenham ajudado a esclarecer o papel das várias populações microbianas na produção de petróleo e gás natural, as implicações mais amplas ainda são uma área emergente de pesquisa. Muitas dessas populações, ao se estabelecerem em poços de extração, provocam impactos econômica e ambientalmente negativos (MAGOT; OLLIVIER; PATEL, 2000).

As bactérias redutoras de sulfato (BRS) são problemáticas, uma vez que são responsáveis pela geração biológica de sulfeto de hidrogênio $\left(\mathrm{H}_{2} \mathrm{~S}\right)$. Essa substância está diretamente ligada ao souring, o qual ocasiona a acidificação dos reservatórios de petróleo e gás, causando efeitos nocivos à indústria. A forma convencional de controle microbiano nos poços é a injeção de biocidas, contudo essa técnica apresenta desvantagens econômicas, ambientais e baixa eficiência em certas condições, o que demonstra a necessidade de investigação de novas alternativas e/ou aprimoramento das já utilizadas (ZARASVAND; RAI, 2014).

Uma alternativa que vem sendo proposta é o uso de vírus bacteriófagos específicos, que são capazes de infectar as bactérias causando a sua lise celular. Trata-se de uma alternativa interessante, já que uma das principais vantagens em relação ao uso de biocida é a sua capacidade de multiplicação, que aumenta por si só a concentração do vírus ao longo do tratamento (ZARASVAND; RAI, 2014).

O uso de coquetéis ou de fagos polivalentes aumenta as chances de sucesso no controle microbiano na área ambiental porque amplia o espectro de hospedeiros infectados (HU; MIYANAGA; TANJI, 2012).

Os bacteriófagos (fagos) apresentam características que possibilitam sua aplicação em diversas áreas, como a medicina e, mais recentemente, a engenharia, garantindo seu uso como agente de controle microbiano, no entanto os fatores que influenciam esse processo ainda requerem muita pesquisa e estudo para consolidar essa técnica, especialmente na área ambiental, em que é comum a formação de biofilmes e a heterogeneidade bacteriana (HU; MIYANAGA; TANJI, 2012).

Ainda não foi estabelecida uma metodologia específica para o estudo de fagos presentes em amostras de água oriundas de poços de petróleo. Embora as amostras tenham composição complexa, alguns estudos foram realizados com a aplicação dos métodos amplamente utilizados na área de ecologia de vírus em ambientes aquáticos (GIMENES, 2010; WILLIAMSON; WOMMACK; RADOSEVICH, 2003).

Para a obtenção dos vírus, o material particulado em suspensão na água precisa ser separado da fase aquosa e ambas as frações devem ser tratadas separadamente. As amostras de água precisam passar primeiramente por um processo de clarificação por centrifugação em baixa rotação para a remoção de material particulado e biológico, e, então os vírus presentes na fração aquosa (sobrenadante) podem ser concentrados por diferentes técnicas: filtração, ultracentrifugação (PAUL et al., 2005;
SUTTLE; CHAN; COTTRELL, 1990; WOMMACK; COLWELL, 2000), ou ainda pelo emprego de uma combinação das técnicas (MEHNERT; STEWIEN, 1993). Os vírus adsorvidos ao material particulado são eluídos e separados dele também por processo de centrifugação. O método Viradel (virus adsorption and elution) vem sendo recomendado desde a 14 a edição do Standard Methods for the Examination of Water and Wastewater (APHA; WWA; WEF, 1976) e, para muitos autores, ainda é considerado a melhor alternativa para a concentração de vírus presentes e amostras ambientais (GARRAFA, 2009; BOSCH et al., 2008).

Shields e Farrah (1986) demonstraram em seus estudos que os bacteriófagos são sensíveis a pH extremos, assim, as técnicas que empregam membranas carregadas negativamente são pouco eficientes para a recuperação desses tipos virais, sugerindo então o uso de membranas carregadas positivamente. Para aumentar a eficiência da eluição tem sido utilizada solução proteica à base de extrato de carne. Na recuperação viral de bacteriófagos T4 presentes em solo, com extrato de carne como eluente, o índice de recuperação foi de 16\% (WILLIAMSON; WOMMACK; RADOSEVICH, 2003).

Para a detecção viral, geralmente é adotado o método tradicional de plaqueamento, observando-se a formação de placas de lise bacteriana (SUTTLE, 2007). Porém, quando se trata das BRS, depara-se com a dificuldade de cultivá-las, por serem bactérias anaeróbias. Assim, é necessário criar um sistema de cultivo das células na ausência de oxigênio (SUTTLE, 2007; MADIGMAN et al., 2010).

Considerando a importância da eliminação das BRS do sistema de extração de petróleo e a falta de conhecimento sobre a presença de fagos em poços de petróleo para fins de controle do souring, o presente trabalho teve por objetivo estabelecer um método para a concentração de bacteriófagos de BRS presentes nesses poços, avaliando a recuperação viral de amostras de água de reatores semeadas experimentalmente com fagos P1.

\section{MATERIAIS E MÉTODOS}

As determinações analíticas dos reatores foram realizadas no Laboratório de Tratamento Biológico de Resíduos (LTBR), na Universidade Federal de Santa Catarina (UFSC). Já os ensaios microbiológicos foram realizados no Laboratório de Vírus Entéricos Humanos e Animais do Departamento de Microbiologia, no Instituto de Ciências Biomédicas II da Universidade de São Paulo (ICB II/USP).

\section{Manutenção do sistema}

A matriz do presente estudo é um consórcio microbiano oriundo da água de produção de um reservatório de petróleo, operado em offshore e alimentado desde 2007 com meio para crescimento de (BRS e bactérias nitrato-redutoras (BRN). O sistema foi disposto em dois reatores com volume útil de $10 \mathrm{~L}$, operado em regime de batelada alimentada. 
A alimentação dos reatores é composta de água do mar sintética, como mostra a Tabela 1, acrescida de uma solução de elementos traço, descrita na Tabela 2. A alíquota de água do mar a ser utilizada foi enriquecida no momento de uso com $130 \mathrm{mg} . \mathrm{L}^{-1}$ de acetato de sódio, $30 \mathrm{mg} . \mathrm{L}^{-1}$ de propionato de cálcio e $26,66 \mathrm{mg} . \mathrm{L}^{-1}$ de nitrato.

\section{Processamento das amostras}

Para a realização do presente estudo, foram coletadas amostras de água de dois reatores em dezembro de 2016, sendo um volume de $1 \mathrm{~L}$ dos reatores e de $100 \mathrm{~mL}$ do sedimento, após decantação por $48 \mathrm{~h}$. O procedimento foi idêntico para ambos os reatores.

As amostras foram transportadas e processadas no Laboratório de Vírus Entéricos Humanos e Animais, ICBII/USP, sob refrigeração, e mantidas por $24 \mathrm{~h}$ a $4^{\circ} \mathrm{C}$ para decantação do sedimento. As duas frações, o sedimento e o sobrenadante, foram tratadas separadamente, conforme demonstra a Figura 1.

As amostras de água foram clarificadas por centrifugação a $6.000 \mathrm{xg}$, por $15 \mathrm{~min}$ a $4^{\circ} \mathrm{C}$, e o sedimento recolhido até que todo o volume fosse processado. A fase aquosa foi estocada a $-20^{\circ} \mathrm{C}$ até o momento de uso. O sedimento obtido após clarificação de cada uma das amostras foi reservado para a recuperação dos vírus adsorvidos. $\mathrm{O}$ sedimento

Tabela 1 - Composição da água do mar sintética para abastecimento dos reatores.

\begin{tabular}{|c|c|}
\hline Componente & Quantidade (g. $\left.\mathrm{L}^{-1}\right)$ \\
\hline $\mathrm{KH}_{2} \mathrm{PO}_{4}$ & 0,088 \\
\hline $\mathrm{Na}_{2} \mathrm{SO}_{4}$ & 4,408 \\
\hline $\mathrm{NaCl}$ & 24,861 \\
\hline $\mathrm{MgCl}_{2} \cdot 6 \mathrm{H}_{2} \mathrm{O}$ & 9,786 \\
\hline $\mathrm{KCl}$ & 0,820 \\
\hline $\mathrm{CaCl}_{2} \cdot 2 \mathrm{H}_{2} \mathrm{O}$ & 1,588 \\
\hline $\mathrm{NaHCO}_{3}$ & 0,198 \\
\hline $\mathrm{KBr}$ & 0,076 \\
\hline $\mathrm{KI}$ & 0,013 \\
\hline $\mathrm{F}_{2} \mathrm{SO}_{4} \cdot 7 \mathrm{H}_{2} \mathrm{O}$ & 0,025 \\
\hline $\mathrm{SrCl}_{2} \cdot 6 \mathrm{H}_{2} \mathrm{O}$ & 0,030 \\
\hline Solução elementos traço & $1 \mathrm{~mL} \cdot \mathrm{L}^{-1}$ \\
\hline
\end{tabular}

Tabela 2 - Solução de elementos traço.

\begin{tabular}{l|c} 
Componente & $\mathrm{mg} \cdot \mathrm{L}^{-1}$ \\
$\mathrm{CuSO}_{4} \cdot 5 \mathrm{H}_{2} \mathrm{O}$ & 5 \\
\hline $\mathrm{H}_{3} \mathrm{BO}_{3}$ & 10 \\
\hline $\mathrm{MnSO}_{4} \cdot 5 \mathrm{H}_{2} \mathrm{O}$ & 10 \\
\hline $\mathrm{ZnSO}_{4} \cdot 7 \mathrm{H}_{2} \mathrm{O}$ & 70 \\
\hline $\mathrm{MoO}_{3}$ & 10 \\
\hline Água destilada & $1 \mathrm{~L}$ \\
\hline
\end{tabular}

Fonte: Muyzer e Stams (2008). oriundo originalmente dos dois reatores também foi centrifugado por causa do grande volume de água ainda presente, de modo que a massa obtida no fim foi equivalente a $15 \mathrm{~g}$.

O sedimento foi ressuspenso em $200 \mathrm{~mL}$ de solução de extrato de carne (3\%) contendo 0,5 M de glicina, com o meio em pH 9 (BE-GLY), sob agitação magnética constante, por $10 \mathrm{~min}$, a $25^{\circ} \mathrm{C}$, para eluição viral. Em seguida, a mistura foi clarificada por centrifugação a $6.000 x \mathrm{~g}$, por $15 \mathrm{~min}, \mathrm{a} 4^{\circ} \mathrm{C}$, em centrífuga refrigerada (Hettich EBA 12R). O sobrenadante resultante do processo teve o seu $\mathrm{pH}$ ajustado para $7 \mathrm{e}$ foi armazenado a $4^{\circ} \mathrm{C}$ para processamento futuro. Sobre o sedimento, adicionou-se extrato de carne (3\%) contendo $0,5 \mathrm{M}$ de glicina, com o meio em pH 6 (BE-GLY). Repetindo o processo de clarificação, o sedimento foi ressuspenso em tampão fosfato $1 \mathrm{M} \mathrm{pH}$ 7,5. O sobrenadante passou novamente pelo processo de clarificação, em que o sedimento foi tratado com extrato de carne (3\%) contendo $0,5 \mathrm{M}$ de glicina com o meio em pH 9 (BE-GLY), e foi mantido sob agitação magnética constante por 10 min à temperatura ambiente. Então repetiu-se o processo de clarificação. As amostras da fase aquosa e de eluato do sedimento foram ultracentrifugadas a $100.000 \times \mathrm{g}$ por $2 \mathrm{~h} \mathrm{a} 4^{\circ} \mathrm{C}$, para concentração viral em ultracentrífuga Optima XPN $\left(\right.$ Beckman $\left.^{\circledR}\right)$, utilizando rotor SW 28. Após a concentração viral, os sedimentos foram ressuspensos em tampão fosfato $1 \mathrm{M} \mathrm{pH} \mathrm{7,5} \mathrm{(MEHNERT;}$ STEWIEN, 1993) e os sobrenadantes descartados.

Todas as amostras obtidas após a concentração viral foram submetidas ao tratamento com Vertrel XF $(1,1,1,2,3,4,4,5,5,5,5,5-$ decafluoropentano, Clarus ${ }^{\circledR}$, Hortolândia, SP), com o intuito de reduzir proteínas e lipídios. Uma alíquota de $500 \mu \mathrm{L}$ de cada amostra foi misturada com o mesmo volume de Vertrel $\mathrm{XF}^{\circledR}$ (volume por volume - v/v), e processada conforme descrito por Queiroz et al. (2001). O procedimento foi repetido duas vezes. A fase aquosa de cada amostra foi recolhida cuidadosamente e estocada a $-20^{\circ} \mathrm{C}$ até o momento de uso.

\section{Cultivo e quantificação viral}

E. coli MG1655 e fago P1 foram processados segundo método in house adotado no Laboratório de Genética Bacteriana do Prof. Dr. Benny Spira (ICBII/USP). A bactéria E. coli foi cultivada em meio Luria Bertani (LB) por $18 \mathrm{~h}$. Em seguida, realizou-se o subcultivo da bactéria na proporção de 1:100 em $10 \mathrm{~mL}$ em meio LB suplementado com $5 \mathrm{mM}$ $\mathrm{CaCl}_{2}$ e $0,2 \%$ de glicose. $\mathrm{O}$ crescimento bacteriano foi acompanhado por medições de densidade óptica (OD) na absorbância de $600 \mathrm{~nm}$ $\left(\mathrm{OD}_{600}\right)$, em espectrofotômetro (Pharmacia Biotech Ultrospec 1000). Quando atingiu o valor de 0,3 a $0,5 \mathrm{OD}_{600}$, inoculou-se uma alíquota de $200 \mu \mathrm{L}$ da suspensão de bacteriófago P1.

A cultura foi incubada a $37^{\circ} \mathrm{C}$, sob agitação a $250 \mathrm{rpm}$, em shaker, por aproximadamente $3 \mathrm{~h}$. Quando a suspensão ficou translúcida em decorrência da lise das bactérias, adicionaram-se $100 \mu \mathrm{L}$ de clorofórmio e agitou-se a mistura novamente no shaker por $5 \mathrm{~min}$. Essa mistura foi centrifugada a $9.500 \times \mathrm{g}$, por $10 \mathrm{~min}$, a $4^{\circ} \mathrm{C}$. O sedimento foi 
descartado e o sobrenadante acondicionado em um novo tubo, ao qual foram acrescidos mais $10 \mu \mathrm{L}$ de clorofórmio. A alíquota foi armazenada a $4^{\circ} \mathrm{C}$ até o momento de uso.

A suspensão de fago P1 obtida foi concentrada por ultracentrifugação a $100.000 \times \mathrm{g}$, por $2 \mathrm{~h}$, a $4^{\circ} \mathrm{C}$ em ultracentrífuga Optima XPN $\left(\right.$ Beckman $^{\circledR}$ ), com rotor SW 28 (MEHNERT; STEWIEN, 1993). Os fagos sedimentados foram ressuspensos em tampão fosfato $1 \mathrm{M} \mathrm{pH} \mathrm{7,5,} \mathrm{em}$ um volume calculado para obtenção de um fator de concentração de 300 vezes e armazenados a $4^{\circ} \mathrm{C}$ até o momento de uso.

O protótipo viral concentrado foi titulado por método de plaqueamento, utilizando os meios LB Agar (20 g de LB [Life Technologies]) e
$8 \mathrm{~g}$ de Agar Bacteriological [Acumedia]) e Top Agar, suplementado com $5 \mathrm{mM} \mathrm{CaCl}_{2}, 0,1 \mathrm{M} \mathrm{MgSO}_{4}$ e $0,2 \%$ de glicose, misturado com $200 \mathrm{~mL}$ E. coli $\left(0,3 \mathrm{OD}_{600}\right)$. Diluições seriadas de fator 10 do protótipo viral P1 variando de $10^{-1}$ a $10^{-7}$ foram preparadas em solução salina $0,9(\mathrm{v} / \mathrm{v}) \mathrm{e}$ volumes de $10 \mu \mathrm{L}$ de cada diluição foram adicionados sobre o Top Agar na respectiva demarcação na placa de Petri. As placas foram incubadas em estufa a $37^{\circ} \mathrm{C}$, por um período de 6 a $12 \mathrm{~h}$. As placas de lise foram observadas com lupa estereoscópica e contadas na menor diluição. Determinou-se o título viral matematicamente, seguindo a Equação 1:

$\mathrm{UFP} / 10 \mu \mathrm{L}=$ Média UFP $/ 10 \mu \mathrm{L}$ x Fator de diluição

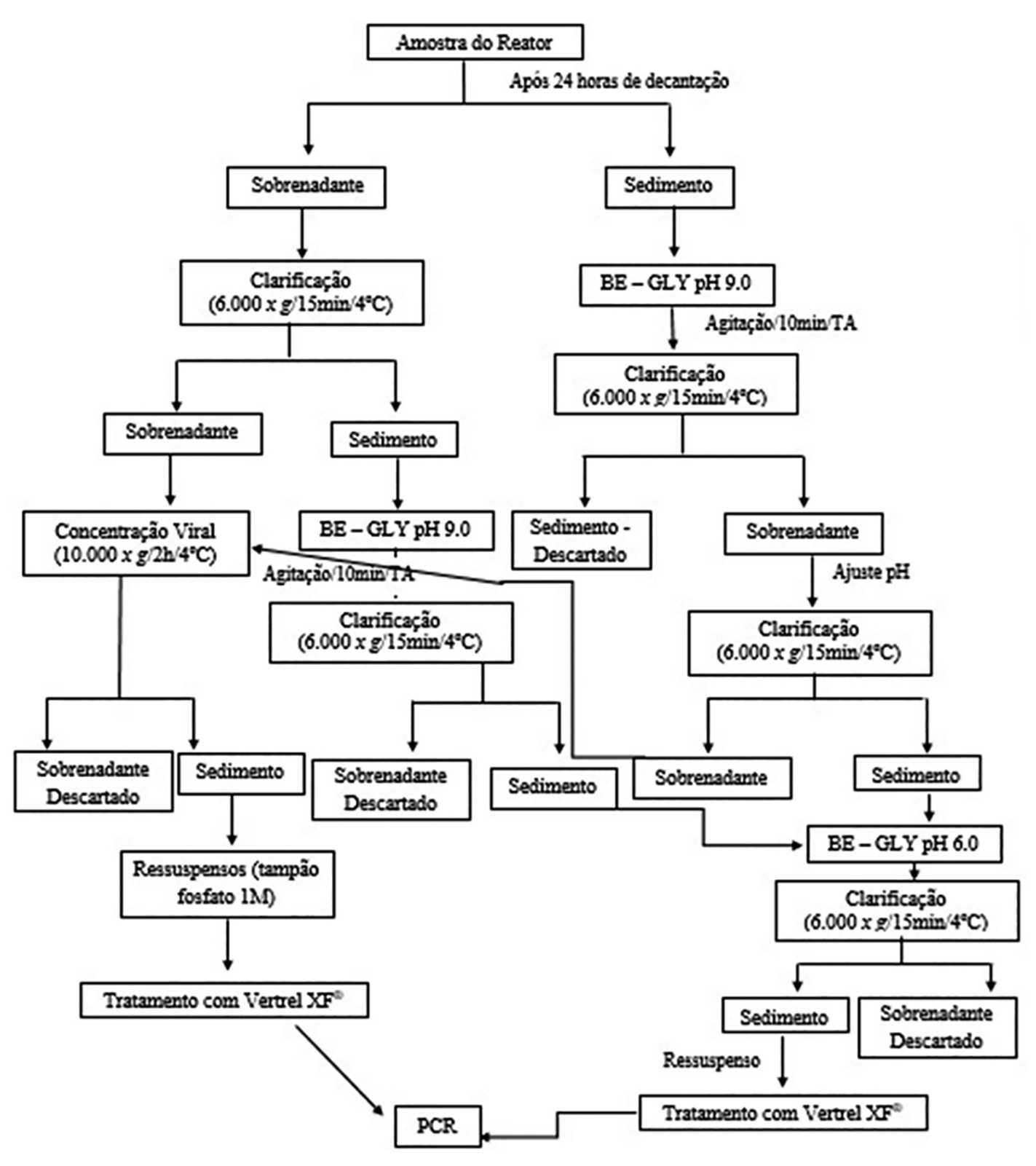

Figura 1 - Representação esquemática do processamento da amostra. 
Para as amostras concentradas por ultracentrifugação, o título foi determinado matematicamente pela Equação 2:

$$
\mathrm{UFP} / 10 \mu \mathrm{L}=\frac{\begin{array}{c}
\mathrm{UFP} / 10 \mu \mathrm{L} \times \text { fator de diluição } \times \\
\text { fator de correção do volume }
\end{array}}{\text { fator de concentração }}
$$

Em que:

$\mathrm{UFP}=$ unidades formadoras de placas.

Os resultados foram expressos em unidades formadoras de placa por volume $(\mathrm{UFP} / \mu \mathrm{L})$.

\section{Avaliação da recuperação de fago P1 em amostras de água do reator}

Três amostras de água coletadas do reator, com o volume de $100 \mathrm{~mL}$ cada, foram semeadas com $1 \mathrm{~mL}$ de suspensão de fago P1 contendo $5 \times 10^{5} \mathrm{UFP} / 1 \mathrm{~mL}$ e mantidas sob agitação magnética constante por 30 min, à temperatura de $25^{\circ} \mathrm{C}$.

Em seguida, as amostras foram clarificadas por centrifugação a $6.000 x \mathrm{~g}$, por $15 \mathrm{~min}$, a $4^{\circ} \mathrm{C}$. O sobrenadante foi estocado a $4^{\circ} \mathrm{C}$ para posterior processo de concentração viral, originando as amostras P1A, P1B e P1C.

O sedimento obtido após clarificação foi tratado com extrato de carne (BE-GLY) para eluição viral. Um volume de $30 \mathrm{~mL}$ de extrato de carne (3\%) contendo 0,5 M de glicina com o meio em pH 9 (BE-GLY) foi adicionado ao sedimento, e a mistura foi mantida sob agitação magnética constante por $10 \mathrm{~min}$, a $25^{\circ} \mathrm{C}$. A mistura foi clarificada conforme descrito. $\mathrm{O}$ sedimento foi descartado, o sobrenadante transferido para um novo tubo e o $\mathrm{pH}$ ajustado para $7 \mathrm{e}$ armazenado a $4^{\circ} \mathrm{C}$ para posterior processo de concentração viral. Essas amostras foram denominadas de P2A, P2B e P2C.

Em seguida, as amostras foram concentradas por ultracentrifugação conforme descrito anteriormente. Uma alíquota de cada amostra foi armazenada a $4^{\circ} \mathrm{C}$ para titulação por plaqueamento e o restante das amostras foi tratado com Vertrel $\mathrm{XF}^{\oplus}$, conforme descrito.

\section{Análise estatística}

Para analisar a percentagem de recuperação viral, realizou-se o teste estatístico do $\chi^{2}$. O nível de significância adotado foi de $5 \%$ (valor de $\mathrm{p}<0,05(5 \%))$ (DE GROOT, 1986).

\section{RESULTADOS E DISCUSSÃO}

Para a padronização e realização dos ensaios moleculares de detecção de bacteriófagos, foram cultivadas linhagens suscetíveis ao protótipo P1. Esse fago é classificado na família Myoviridae, infecta E. coli e vem sendo utilizado como modelo para estudo de métodos por ser um fago temperado, que lisa a célula hospedeira (LOBOCKA et al., 2004).
No presente estudo, usou-se E. coli MG1655 como hospedeira para o fago P1, por ser uma cepa de laboratório com mínima manipulação genética. Blattner et al. (1997) adotaram a mesma cepa de E. coli para determinar o genoma completo do bacteriófago P1.

A presença do protótipo viral é revelada por método de plaqueamento baseado na visualização de placas de lise decorrentes da infecção causada pelo bacteriófago P1 na cultura de E. coli. A contagem de placas de lise é a metodologia tradicional para detecção de bacteriófagos. Apresenta a desvantagem de que fagos com cauda podem exibir placas de lise muito pequenas, grandes ou uma placa de difusão no meio de cultura, contudo é por meio dessa técnica que é possível obter informações sobre a infectividade dos bacteriófagos e das células hospedeiras (ROSERO, 2009). Considerando-se o número de placas de lise observado antes da etapa de concentração viral e com base em cálculos matemáticos, determinou-se a presença de $5 \times 10^{7}$ UFP de P1 em $10 \mu \mathrm{L}$ de suspensão. Após o processo de concentração viral foi determinada a concentração de $4 \times 10^{10} \mathrm{UFP} / 10 \mu \mathrm{L}$.

Vários métodos de concentração viral de amostras ambientais foram propostos nos últimos anos, contudo nenhum foi estabelecido como padrão. Vale ressaltar que a maior parte dos métodos foi desenvolvida para a concentração de enterovírus, com o intuito de realizar monitoramento viral diante do problema de saúde pública decorrente de poliomielite (BOSCH et al., 2008; CHO et al., 2000). No desenvolvimento da virologia ambiental, esses métodos foram empregados para a concentração de outros vírus entéricos, como os rotavírus, norovírus, vírus da Hepatite A, entre outros (WYN-JONES; SELLWOOD, 2001; BOSCH et al., 2008; GARRAFA, 2009).

A literatura sugere o uso do método Viradel (virus adsorption and elution), considerado a melhor alternativa para a concentração de vírus presentes em amostras ambientais, que se baseia na adsorção das partículas virais a filtros de microporosidade ou outros substratos, e posterior eluição com pequenos volumes (BOSCH et al., 2008).

Para a concentração das amostras foi realizada uma adaptação do método proposto por Mehnert e Stewien (1993), que é baseado no método Viradel, seguido de ultracentrifugação. Tal método vem sendo utilizado desde 1988 pelo grupo de pesquisa do Laboratório de Vírus Entéricos Humanos e Animais (ICB/USP) para pesquisa de rotavírus, adenovírus e vírus em amostras de solo, esgoto, águas superficiais (MEHNERT et al., 1997; QUEIROZ et al., 2001; GARRAFA, 2009; PAULI, 2003; SANTOS et al., 2004; PIRANHA et al., 2006; SASSAROLI, 2002).

A escolha da técnica foi definida pelo tipo de amostra. Assim, optou-se pelo uso da centrifugação para clarificação das amostras, seguida do processo de eluição e da ultracentrifugação.

O processo de clarificação é indicado para a redução de resíduos particulados indesejáveis geralmente em suspensão na água e que podem interferir no processo de concentração.

Já o método de concentração viral por adsorção/eluição a sais se baseia na propriedade dos vírus de adsorverem eletrostaticamente a 
essas substâncias. Diferentes tipos de materiais vêm sendo empregados, como óxido de ferro, fosfato, hidróxido de alumínio, extrato de carne ou carvão ativado (FONG; LIPP, 2005; WYN-JONES; SELLWOOD, 2001).

O extrato de carne foi utilizado como eluente, uma vez que Shields e Farrah (1986) demonstraram em seus estudos que os bacteriófagos são sensíveis a pH extremos, além de aumentar a eficiência na eluição. É constituído de grandes moléculas orgânicas, as quais rompem as ligações hidrofóbicas entre os bacteriófagos e superfícies aderidas, o que o torna um melhor eluente que os demais, citrato de potássio ou pirofosfato de sódio (WILLIAMSON; WOMMACK; RADOSEVICH, 2003).

Diante da alta eficiência do extrato de carne, optou-se pelo seu uso para eluição das partículas virais que poderiam estar aderidas aos sedimentos do reator.

A ultracentrifugação consiste na utilização de força gravitacional superior a $100.000 \times \mathrm{g}$, por $1 \mathrm{~h}$, para possibilitar a sedimentação de partículas virais. Esse método é indicado para a análise de pequenos volumes (MEHNERT et al., 1997; WYN-JONES; SELLWOOD, 2001). Ao comparar o volume processado em outros trabalhos na área ambiental com o presente estudo, que processou $2.200 \mathrm{~mL}$ de amostra, percebe-se que o método escolhido é o mais indicado. Para o estudo que avaliou a qualidade virológica do efluente doméstico tratado e disponibilizado para reúso na cidade de São Paulo, foram utilizados volumes de $15 \mathrm{~L}$ de esgoto bruto e $100 \mathrm{~L}$ de esgoto tratado (GARRAFA, 2009). A pesquisa que visou analisar a população de vírus das famílias Phycodnaviridae e Myoviridae nos rios Cuieiras, Negro e Solimões se baseou no volume de 200 L de água para cada amostra (GIMENES, 2010).

Para Seeley e Primrose (1982), o método de ultracentrifugação apresenta as vantagens de ser rápido e não seletivo, contudo apresenta as desvantagens do processamento de pequenos volumes de amostra. Ainda assim, optou-se pelo uso dessa técnica por ser eficiente, simples e rápida.
Após a concentração viral, as amostras foram divididas em duas alíquotas, uma das quais foi tratada com o reagente Vertrel $\mathrm{XF}^{\circledR}$ e a outra não.

O Vertrel $\mathrm{XF}^{\circledR}$ é composto de hydrofluorocarbon (2,3-dihydrodeca-fluoropentane) com trans-1,2-dichloroethylene. Tal solvente foi criado após a proibição do uso da substância Freon TF em razão da emissão de gases que afetavam a camada de ozônio, auxiliando o fenômeno de aquecimento global. O Vertrel XF ${ }^{\circledR}$ é aceito pela Agência de Proteção Ambiental dos Estados Unidos (United States Environmental Protection Agency - EPA) sob o programa da Política de Novas Alternativas Significativas (SNAP), como substituto de substâncias que destroem o ozônio (DUPONT, 2017).

Seu uso é adequado para remoção de lipídios, limpeza de partículas do solo, remoção de partículas (DUPONT, 2017). Assim, o Vertrel XF ${ }^{\circledR}$ vem sendo amplamente utilizado para limpeza de amostras ambientais, uma vez que a presença de resíduos pode afetar as análises moleculares subsequentes, bem como a extração de DNA (GARRAFA, 2009; GIMENES, 2010).

Para avaliar a recuperação viral, o protótipo miofago P1 $\left(5 \times 10^{5} \mathrm{UFP} / 1 \mathrm{~mL}\right)$ foi semeado experimentalmente nas amostras de água do reator, recuperado e purificado pelo método proposto, tanto do sedimento como do sobrenadante. Os resultados desses ensaios são apresentados na Tabela 3 .

Ao submeter os resultados obtidos ao teste do $\chi^{2}$, observou-se que o valor de $\mathrm{p}$ ( $p$-value) obtido da análise entre P1 e P2 antes do tratamento das amostras com Vertrel $\mathrm{XF}^{\circledR}$ foi de 0,195 , indicando que não há diferenças estatisticamente significantes da recuperação em amostras processadas com base no sobrenadante (P1) e no sedimento (P2).

Já na análise entre P1 e P2 após o tratamento com Vertrel $\mathrm{XF}^{\oplus}$, o percentual total de recuperação do lisado apresentou valores próximos a 0 , indicando a existência de diferenças estatisticamente significantes entre as amostras.

Tabela 3 - Índice de recuperação do método de concentração viral aplicado a amostras de água do reator determinado por titulação.

\begin{tabular}{|c|c|c|c|c|c|c|c|}
\hline $\begin{array}{l}\text { Tratamento das amostras } \\
\text { com Vertrel XF }\end{array}$ & Ensaio & $\begin{array}{l}\text { Lisado semeado } \\
\text { UFP/mL }\end{array}$ & \multicolumn{2}{|c|}{ Recuperado UFP/mL } & $\begin{array}{l}\text { Total recuperado } \\
\text { UFP/mL (P1+P2) }\end{array}$ & \% Recuperação & $\begin{array}{l}\text { \% Recuperação } \\
\text { Total }\end{array}$ \\
\hline \multirow{2}{*}{ Antes } & A & \multirow{2}{*}{$5 \times 10^{5}$} & $2,6 \times 10^{4}$ & $7 \times 10^{4}$ & $9,6 \times 10^{4}$ & $19,20 \%$ & \multirow{2}{*}{$17,5 \% *$} \\
\hline & C & & $3 \times 10^{4}$ & $9 \times 10^{4}$ & $1,2 \times 10^{5}$ & $24 \%$ & \\
\hline \multicolumn{3}{|l|}{ Valor de $\mathrm{p}^{\mathrm{a}}$} & \multicolumn{2}{|c|}{$<0,195$} & & & \\
\hline \multirow[t]{2}{*}{ Depois } & B & \multirow[t]{2}{*}{$5 \times 10^{5}$} & $4 \times 10^{4}$ & $7 \times 10^{4}$ & $1,1 \times 10^{5}$ & $22 \%$ & \multirow[t]{2}{*}{$27,7 \%^{* \star}$} \\
\hline & $C$ & & $4,5 \times 10^{4}$ & $1,2 \times 10^{5}$ & $1,6 \times 10^{5}$ & $33 \%$ & \\
\hline \multicolumn{3}{|l|}{ Valor de $\mathrm{p}^{\mathrm{b}}$} & \multicolumn{2}{|c|}{$<0,03$} & & & \\
\hline \multicolumn{7}{|l|}{ Valor de $\mathrm{p}^{c}$} & $<0,001$ \\
\hline
\end{tabular}


A recuperação viral média obtida pelo método de concentração foi de $17,5 \%$ para as amostras antes do tratamento com Vertrel $\mathrm{XF}^{\circledR} \mathrm{e}$ de $27,7 \%$ após o uso do reagente, demonstrando que este foi eficiente para a remoção de lipídios e proteínas das amostras e consequentemente causou maior recuperação das partículas virais que estão aderidas ao material particulado.

Muitos estudos baseados no método Viradel adotam a filtração em membranas eletricamente carregadas, sendo positivas ou negativas para adsorção viral, seguida de eluição com substâncias proteicas, entre elas extrato de carne (SOBSEY; JONES, 1979; RAO; METCALF; MELNICK, 1986). As eficiências de recuperação são bastante variáveis, dependendo tanto da matriz ambiental como dos tipos virais pesquisados, e pode variar de 20 a 30\% para poliovírus a 90\% para rotavírus (MEHNERT; STEWIEN, 1993; QUEIROZ et al, 2001), entretanto a concentração de fagos é mais complexa, pela própria estrutura das partículas virais.

Williamson, Wommack e Radosevich (2003) avaliaram os métodos de recuperação viral adequados para posterior análise de detecção de bacteriófagos (plaqueamento, microscopia de fluorescência e microscopia eletrônica de transmissão). No presente estudo foram testados quatro tampões de eluição (extrato de carne, tampão de glicina, pirofosfato de sódio e citrato de potássio).

O extrato de carne apresentou eficiência de $26 \%$ na recuperação de bacteriófagos, contudo, ao se analisar a recuperação viral de bacteriófagos T4 em solo utilizando extrato de carne como eluente, o índice de recuperação foi de 16\% (WILLIAMSON; WOMMACK; RADOSEVICH, 2003). Isso demonstra que o índice de recuperação de bacteriófagos da família Myoviridae, alvo do presente estudo, superou o esperado na literatura.

A recuperação viral de 27,7\% demonstra que o método aplicado é eficiente para a eluição dos bacteriófagos presentes nas amostras, o que indica que o método proposto, como um todo, pode ser aplicado na extração de bacteriófagos presentes em amostras oriundas de água do reator.

\section{CONCLUSÕES}

O processamento das amostras, que consistiu nas etapas de clarificação, eluição com extrato de carne, ultracentrifugação e tratamento das amostras com Vertrel XF ${ }^{\circledR}$, mostrou eficiência maior para recuperação de miofagos semeados experimentalmente em amostras de água de reator de poço de petróleo do que o reportado até o momento na literatura.

\section{AGRADECIMENTOS}

Ao professor doutor Beny Spira, do Laboratório de Genética Bacteriana do Departamento de Microbiologia do Instituto de Ciências Biomédicas da Universidade de São Paulo, por ceder a bactéria E. coli MG1655 e o protótipo fago P1; e a seus colaboradores doutor Luis Gustavo de Almeida e mestre Henrique Iglesias Neves, o auxílio nos ensaios de fagos; à professora doutora Silvana Cai, do Laboratório de Microbiologia Oral do Departamento de Microbiologia do Instituto de Ciências Biomédicas da Universidade de São Paulo, por disponibilizar a infraestrutura laboratorial para crescimento bacteriano.

\section{REFERÊNCIAS}

AMERICAN PUBLIC HEALTH ASSOCIATION (APHA); AMERICAN WATER WORKS ASSOCIATION (AWWA); WATER ENVIRONMENT FEDERATION (WEF). (1976) Standard methods for the examination of water and wastewater. 14. ed. Washington, D.C.: American Public Health Association.

BLATTNER, F.R.; PLUKETT III, G.; BLOCH, C.A.; PERNA, N.T; BURLAND, V.; RILEY, M.; COLLADO-VIDES, J.; GLASNER, J.D.; RODE, C.K.; MAYHEW, G.F.; GREGOR, J.; DAVIS, N.W.; KIRKPATRICK, H.A.; GOEDEN, M.A.; ROSE, J.; MAU, B.; SHAO, Y. (1997) The complete genome sequence of Escherichia coli K-12. Science, v. 277, n. 5331, p. 1453-1462. http://doi.org/10.1126/science.277.5331.1453

BOSCH, A.; GUIX, S.; SANO, D.; PINTÓ, R.M. (2008) New tools for the study and direct surveillance of viral pathogens in water. Elsevier, v. 19, n. 3, p. 295-301. https://doi.org/10.1016/j.copbio.2008.04.006

CHO, H.B.; LEE, S.H.; CHO, J.C.; KIM, S.J. (2000) Detection of adenovirus and enteroviruses in tap water and river water and river water by reverse transcription multiplex PCR. Canadian
Journal of Microbiology, v. 46, n. 5, p. 417-424. https://doi.org/10.1139/ cjm-46-5-417

DE GROOT, M. (1986) Probability and statistics. 2. ed. Nova York: Addison-Wesley.

DUPONT. (2007) DuPont ${ }^{T M}$ Vertre $^{\circledR}$ SFR. Disponível em: <https:// www.chemours.com/Vertrel/en_US/assets/downloads/pdf/k22198_ it.pdf>. Acesso em: 8 fev. 2017

FONG, T.T.; LIPP, E.K. (2005) Enteric viruses of Humans and Animals in aquatic environments: health risks, detection and potential water quality assessment tools. Microbiology and Molecular Biology Review, v. 69, n. 2, p. 357-371. https://doi.org/10.1128/mmbr.69.2.357-371.2005

GARRAFA, P. (2009) Avaliação da qualidade virológica do efluente doméstico tratado e disponibilizado para reuso na cidade de São Paulo. 146f. Tese (Doutorado em Ciências) - Programa de Pós-Graduação em Microbiologia, Instituto de Ciências Biomédicas, Universidade de São Paulo, São Paulo. 
GIMENES, M.V. (2010) Virioplântion na Amazônia: Estudo da diversidade dos vírus das familias Phycodnaviridae e Myoviridae nos Rios Negro, Solimões e Cuieiras. 115f. Tese (Doutorado em Ciências) Programa de Pós-Graduação em Microbiologia, Instituto de Ciências Biomédicas, Universidade de São Paulo, São Paulo.

HU, J.; MIYANAGA, K.; TANJI, Y. (2012) Diffusion of bacteriophages through artificial biofilm models. Biotechnology Progress, v. 28, n. 2 , p. 319-326. https://doi.org/10.1002/btpr.742

LOBOCKA, M.B.; ROSE, D.J.; PLUNKETT, G.; RUSIN, M.; Samojedny, A.; Lehnherr, H.; Yarmolinsky, M.B.; Blattner, F.R. (2004) Genome of Bacteriophage P1. Journal of Bacteriology, v. 186, n. 21, p. 7032-7068. https://doi.org/10.1128/jb.186.21.7032-7068.2004

MADIGMAN, M.T; MARTINKO, J.M.; DUNLAP, P.V.; CLARCK, D.P. (2010) Microbiologia de Brock. 12. ed. Porto Alegre: Artmed.

MAGOT, M.; OLLIVIER, B.; PATEL, B.K.C. (2000) Microbiology of petroleum reservoirs. Antonie Van Leeuwenhoek International Journal of General and Molecular Microbiology, v. 77, n. 2, p. 103-116. https://doi.org/10.1023/a:1002434330514

MEHNERT, D.U.; STEWIEN, K.E. (1993) Detection and distribution of rotavirus in raw sewage and creeks in São Paulo, Brazil. Applied and Environmental Microbiology, v. 59, n. 1, p. 140-143.

Mehnert, D.U.; Stewien, K.E.; Hársi, C.M.; Queiroz, A.P.S.; Candeias, J.M.G.; CANDEIAS, J. (1997) Detection of rotavirus in sewage and creek water: efficiency of the concentration method. Memórias do Instituto Oswaldo Cruz, v. 92, n. 1, p. 97-100. https://doi. org/10.1590/S0074-02761997000100020

MUYZER, G.; STAMS, A.J.M. (2008) The ecology and biotechnology of sulphate-reducing bacteria. Nature Reviews Microbiology, v. 6, n. 6. p. 441-454. https://doi.org/10.1038/nrmicro1892

Paul, J.H.; Williamson, S.J,; Long, A.; Authement, R.N.; John, D.; Segall, A.M.; Rohwer, F.L.; Androlewicz, M.; Patterson, S. (2005) Complete Genome Sequence of \{phi\} HSIC, a Pseudotemperate Marine Phage of Listonella pelagia. Applied Environmental Microbiology, v. 71, n. 6, p. 3311-3320. https://doi.org/10.1128/aem.71.6.3311-3320.2005

PAULI, V. (2003) Ocorrência e distribuição de genótipos G e P de rotavírus em efluente doméstico e córrego da cidade de São Paulo. 121f. Dissertação (Mestrado em Ciências) - Instituto de Ciências Biomédicas da Universidade de São Paulo, São Paulo.

PIRANHA, J.M.; PACHECO, A.; GAMBA, R.C.; MEHNERT, D.U.; GARRAFA, P.; BARRELLA, K.M. (2006) Faecal contamination (viral and bacterial) detection in Groundwater used for drinking purposes in São Paulo, Brazil. Geomicrobiology, v. 23, n. 5, p. 279-283. https:// doi.org/10.1080/01490450600760708

QUEIROZ, A.P.S; SANTOS, F.M; SASSAROLI, A.; HÁRSI, C.M; MONEZI, T.A; MEHNERT, D.U. (2001) Electropositive filter membrane as an alternative for the elimination of PCR inhibitors from sewage and water samples. Applied and Environmental Microbiology, v. 67, n. 10, p. 4614-4618. https://doi.org/10.1128/aem.67.10.4614-4618.2001
RAO, V.C:; METCALF, T.G.; MELNICK, J.L. (1986) Development of a method for concentration of rotavirus and its application to recovery of rotavirus from estuarine water. Applied and Environmental Microbiology, v. 52, n. 3, p. 484-488.

ROSERO, E.M.B. (2009) Frequência e diversidade de colifagos somáticos isolados de amostras de água do mar, plâncton e bivalves da Baixada Santista, Canal de São Sebastião e Ubatuba. 155f. Tese (Doutorado em Ciências) - Instituto de Ciências Biomédicas, Universidade de São Paulo, São Paulo.

SANTOS, F.M.; VIEIRA, M.J.; GARRAFA, P.; MONEZI, T.A.; PELLIZARI, V.H.; HÁRSI, C.M.; MEHNERT, D.U. (2004) Discrimination of adenovirus types circulating in urban sewage and surface polluted waters in São Paulo city, Brazil. Water Science and Technology: Water Supply, v. 4, n. 2, p. 79-85. https://doi.org/10.2166/ws.2004.0031

SASSAROLI, A. (2002) Virus da Hepatite A: a presença e identificação dos genótipos circulantes nas águas de esgoto e de superfície da cidade de São Paulo, Brasil. 118f. Dissertação (Mestrado em Ciências) - Instituto de Ciências Biomédicas, Universidade de São Paulo, São Paulo.

SEELEY, N.D; PRIMROSE, S.B. (1982) A Review: The isolation of bacteriophages from the environment. Journal of Applied Bacteriology, v. 53, n. 1, p. 1-17. https://doi.org/10.1111/.1365-2672.1982.tb04729.x

SHIELDS, P.A.; FARRAH, S.R. (1986) Concentration of viruses in beef extract by flocculation with ammonium sulfate. Applied and Environmental Microbiology, v. 51, n. 1, p. 211-213.

SOBSEY, M.D.; JONES, B.L. (1979) Concentration of poliovirus from tap water using positively charged microporous filters. Applied and Environmental Microbiology, v. 37, n. 3, p. 588-595. https://doi. org/10.1128/AEM.37.3.588-595.1979

SUTTLE, C.A. (2007) Marine viruses: major players in the global ecosystem. Nature Reviews Microbiology, v. 5, p. 801-812. https:// doi.org/10.1038/nrmicro1750

SUTTLE, C.A.; CHAN, A.M; COTTRELL, M.T. (1990) Infection of phytoplankton by viruses and reduction of primary productivity. Nature, v. 347, p. 467-469. https://doi.org/101038/347467aO

WILLIAMSON, K.E.; WOMMACK, K.E.; RADOSEVICH, M. (2003) Sampling natural viral communities from soil for cultureindependent analyses. Applied Environmental Microbiology, v. 69, n. 11, p. 6628-6633. https://doi.org/10.1128/aem.69.11.6628-6633.2003

WYN-JONES, A.P.; SELLWOOD, J. (2001) Enteric viruses in the aquatic environment. Journal Applied Microbiology, v. 91, n. 6 , p. 945-962. https://doi.org/10.1046/j.1365-2672.2001.01470.x

WOMMACK, K.; COLWELL, R. (2000) Virioplankton: viruses in aquatic ecosystems. Microbiology and Molecular Biology Review, v. 64, n. 1, p. 69-114. https://doi.org/10.1128/mmbr.64.1.69-114.2000

ZARASVAND, K.A.; RAI, V.R. (2014) Microorganisms: Induction and inhibition of corrosion in metals. International Biodeterioration and Biodegradation, v. 87, p. 66-74. https://doi.org/10.1016/j.ibiod.2013.10.023 